\section{Association between "a body shape index" and mortality: Bambuí Cohort Study of Aging, Brazil}

\author{
Associação entre "a body shape index" e mortalidade: \\ o Estudo de Coorte de Idosos de Bambuí, Brasil
}

Asociación entre "a body shape index" y mortalidad: estudio de una Cohorte Ancianos de Bambuí, Brasil
Mary Anne Nascimento-Souza 1 Juliana Vaz de Melo Mambrini 1 Sérgio Viana Peixoto 1,2

Maria Fernanda Lima-Costa 1,3

\begin{abstract}
This article aims to evaluate the joint and separate association between abdominal and general adiposity indicators and mortality. Data was collected from 1,366 older adults in the Bambuí Cohort Study of Aging with complete information for all variables of interest. The outcome variable was allcause time until death; exposure variables were a body shape index (ABSI), waist circumference (WC), waist-to-height ratio (WHtR) and body mass index $(B M I)$, assessed at the beginning of the study, and at the 3 rd, 5th and $11^{\text {th }}$ year of follow-up. Association between the quartiles of anthropometric indicators and mortality was calculated using an extended Cox proportional hazards model and adjusted for socioeconomic and behavioral confounding factors. Older adults in the $4^{\text {th }}$ ABSI quartile had a higher risk of mortality regardless of BMI (1.27; 95\%CI: 1.01-1.58), but this association was not observed in sensitivity analyses. Older adults in the 2nd, 3rd and 4th BMI quartiles had a lower risk of mortality, even when adjusted for WC or ABSI. WC and WHtR showed no association consistent with all-cause mortality after adjustment for confounding factors. Considering the loss of significance in the sensitivity analyses, ABSI's predictive capacity for mortality is still weak. Thus, adopting ABSI in clinical practice or in epidemiological surveys, in conjunction or replacing $B M I$ and $W C$, requires more in-depth studies.
\end{abstract}

Aging; Mortality; Body Mass Index; Waist Circunference; Waist-Height Ratio

\section{Correspondence}

M. A. Nascimento-Souza

Instituto René Rachou, Fundação Oswaldo Cruz.

Av. Augusto de Lima 1715, Belo Horizonte, $M G$ 30190-009, Brasil.

maryannemoc@yahoo.com.br

${ }^{1}$ Instituto René Rachou, Fundação Oswaldo Cruz, Belo Horizonte, Brasil.

2 Escola de Enfermagem, Universidade Federal de Minas Gerais, Belo Horizonte, Brasil

3 Programa de Pós-graduação em Saúde Púbica, Universidade Federal de Minas Gerais, Belo Horizonte, Brasil. 


\section{Introduction}

Previous studies have shown the relationship between overweight and obesity and the risk of mortality from cardiovascular disease, cancer and all-cause 1,2. Most prospective studies assessing the association between overweight and mortality risk used the body mass index (BMI) to evaluate nutritional status 3. Widely applied to predict the risk of different health events related to overweight or obesity, its use has been questioned, as BMI does not distinguish between the accumulation of lean or fat mass or the distribution of adipose tissue 4, i.e., a high BMI may not necessarily reflect an increase in adiposity. Additionally, BMI validity as an adiposity indicator in older adults is limited 5 , as lean mass decreases with aging even without a change in body weight 6 .

Waist circumference (WC), an indicator of abdominal adiposity, has been used to complement BMI assessment. High WC is associated with an increase in the prevalence of cardiovascular disease and in the risk of premature death, even when BMI is within the normal range ${ }^{7}$. Its use to properly estimate body fat distribution, however, is limited since it disregards that taller individuals have a higher WC 8,9. Additionally, the high correlation between WC and BMI hinders determining the independent role of general and abdominal fat as a risk factor for health outcomes 10,11.

Measures derived from WC, such as waist-to-height ratio (WHtR) and waist-to-hip ratio have also been studied, showing high correlation with BMI 12. Considering these limitations, Krakauer \& Krakauer 11 proposed a measure named a body shape index (ABSI), based on WC and adjusted for height and weight. A high ABSI value indicates that WC is greater than expected for a given height and weight, thus corresponding to a more centralized body volume concentration. Thus, ABSI helps quantify the risk associated with abdominal obesity that cannot be attributed to BMI.

ABSI performed better than WC and BMI in predicting the risk of all-cause death in an North American population aged 18 or over, with the authors stressing that their predictive power differed between ethnic groups, with less power for Latinos compared with Caucasians and African Americans 11. In a recent meta-analysis conducted with 24 retrospective cohorts from 15 countries ABSI showed a superior performance in predicting all-cause mortality when compared with WC and BMI 13. Among the included cohorts, no study included only older adults or a Latin American population. To our knowledge, no study have evaluated the association of ABSI with all-cause mortality in the Brazilian population 14 , especially in older adults, a rapidly growing group in developing countries such as Brazil ${ }^{15}$. As the Brazilian population is highly mixed ${ }^{16}$, our study can contribute to assess ABSI applicability and other indirect adiposity measures in different populations.

Moreover, most studies in the literature used only one anthropometric measure, obtained at baseline, to assess the association between ABSI and mortality 13 , which is insufficient to reveal its impact on mortality. Thus, it remains unknown to what extent ABSI varies over time and whether this change would affect the risk of mortality. In this context, this study aimed to assess the joint and separate association of abdominal adiposity indicators (ABSI, WC and WHtR) and BMI with mortality among older adults, using anthropometric measures as time dependent variables.

\section{Methodology}

\section{Study population and data collection}

The Bambui Cohort Study of Aging is a prospective population-based study conducted in the city of Bambuí, a municipality located in the state of Minas Gerais, Brazil, $215 \mathrm{~km}$ from Belo Horizonte. The city had about 15,000 inhabitants when the cohort baseline was established in 1997 17. The baseline population consisted of all residents aged 60 and over on January 1, 1997, identified using a complete city census conducted in 1996 . Out of 1,742 older adults, 1,606 (92.19\%) participated in the interview and 1,454 (83.47\%) underwent physical and laboratory tests.

The cohort's baseline data collection took place from February to May 1997, and from then on, participants were monitored annually by interviews, checking death certificates and physical examinations and collection of biological material, in selected years. Interviews were conducted in the participants' homes and answered by the older adult or by a close relative, when the interviewee was 
unable to answer the questions due to cognitive deficit or other health problem. Clinical and anthropometric evaluation, as well as blood collection for biochemical analysis, took place in the field clinic; in the case of a health limiting condition, the evaluations happened at home. All data were collected by interviewers and previously trained and certified technicians, with at least 11 years of schooling. The present study included data collected between the baseline and December 31, 2011, totaling approximately a 15-year follow-up. Of the 1,606 cohort participants, 1,454 underwent anthropometric measurements at the beginning of the study; of these, 88 (5.48\%) were excluded due to the lack of information for confounding variables, resulting in a final sample of 1,366 older adults.

The Bambuí project was approved by the Ethics Research Committee of the Oswaldo Cruz Foundation (Fiocruz), in Rio de Janeiro on November 4, 1996. All participants signed an Informed Consent Form (ICF) with information about the research, in addition to the authorization to check death records.

\section{Variables of interest and collection procedures}

\section{- Mortality}

The present analysis included all deaths that occurred between the baseline (1997) and December 31, 2011. These were reported by family members during the annual follow-up interviews and confirmed by the Brazilian Ministry of Health's Mortality Information System (SIM). Death certificates were obtained for $98.90 \%$ of the Bambuí cohort participants who had their deaths reported by family members. In the present study, the all-cause time-until-death was the outcome variable.

\section{- Anthropometric assessment}

Weight and height were obtained using standardized techniques and equipment (CMS Weighing Equipment Ltd., London, United Kingdom), with the older adults wearing light clothes and barefoot. Weight was measured using a portable digital electronic scale, with a capacity of $150 \mathrm{~kg}$ and precision of $50 \mathrm{~g}$. Height was measured in the vertical position, using an aluminium stadiometer capable of measuring up to $2 \mathrm{~m}$ and with a $0.1 \mathrm{~cm}$ accuracy. WC was measured using a flexible and inelastic measuring tape at the midpoint between the last rib and the iliac crest, with the interviewee standing up. WHtR was calculated by dividing WC $(\mathrm{cm})$ by height $(\mathrm{cm})$, and BMI by dividing the individual's weight $(\mathrm{kg})$ by height $(\mathrm{m})$ squared. ABSI was calculated using the formula: WC $(\mathrm{m}) \div\left(\mathrm{BMI} 2 / 3 \mathrm{X}\right.$ height $\left.(\mathrm{m})^{1 / 2}\right) 11$.

All these measures were collected in 1997, 2000, 2002 and 2008, using the same procedures. The anthropometric indicators were calculated for these four years and considered as time dependent variables in the association analyses.

\section{- Potential confounding factors}

The variables used to adjust our analyses were obtained at baseline and chosen in line with specialized literature, for they are associated with anthropometric indicators and mortality, especially in older populations 18,19 .

We considered as sociodemographic variables: age (in years), self-reported skin color (white, brown or black), gender (male or female) and schooling (illiterate, 1-3 years and 4 or more years). Health behaviors included current smoking (those who reported having smoked 100 or more cigarettes during their lives and continued to smoke until the time of the interview), at-risk alcohol consumption (seven or more doses per week in the 12 months prior to the interview) and insufficient physical activity (evaluated using metabolic equivalents-MET, less than 450 MET.minutes/week). Estimation of energy expenditure was based on 23 multiple choice questions and two open questions about physical activities performed in the last 90 days, considering all domains. The questions included the type and frequency of the activity and the average time (in minutes) spent on each activity, which allowed to estimate the metabolic equivalents.

As Bambuí was an endemic area for Chagas disease, the analyses considered positive serology for T. cruzi as a potential confounding variable. Infection was defined by positive serology 
in three tests: hemagglutination assay (Biolab Mérieux, Rio de Janeiro, Brazil) and two immunoenzymatic tests (Elisa) (Abbott Laboratories Inc., Chicago, USA; and Wiener Laboratories, Rosario, Argentina).

\section{Statistical analysis}

The descriptive analysis included measures of central tendency and dispersion for quantitative variables and frequency distribution for qualitative variables. Raw mortality rates were estimated using people-years at risk as the denominator. The association between anthropometric indicators (considering the four measures) and time-until-death was assessed using the Cox proportional hazards model, obtaining hazard ratio (HR) estimates and respective 95\% confidence intervals (95\%CI). The anthropometric indicators underwent quartile analysis for better comparability between our results and those of existing studies. The proportionality assumption of risks was tested using Schoenfeld residuals.

As no significant interaction was observed between gender and the anthropometric indicators ( $p$ > 0.05), the results of the extended Cox regression were presented for the entire sample. All variables considered in the analyses were included in the adjusted model only after verifying their collinearity (variance inflation factor $<5$ ).

All models were estimated without adjustments and, subsequently, including the confounding factors. Thus, the association between anthropometric measures and mortality was evaluated by the following models: Model 1 evaluates the association of each anthropometric indicator adjusted for confounding factors; Model 2 evaluates the association of each abdominal adiposity indicator adjusted for BMI (continuous) and other confounding factors; Model 3 evaluates the association of BMI adjusted for WC (continuous) and other confounding factors; and Model 4 evaluates the association of BMI adjusted for ABSI (continuous) and other confounding factors.

Including individuals with diseases in studies that assess the association between excess weight and mortality has been identified as a potential source of bias 20 , as these conditions can lead to weight change and to predisposed higher mortality 21 . Thus, to minimize reverse causality, we performed sensitivity analyses with anthropometric indicators classified in quartiles to verify whether the observed associations would be altered by excluding deaths that occurred in the first two years of follow-up or by excluding those that had chronic diseases at the beginning of the study (i.e., cardiovascular disease, diabetes, hypertension, and arthritis or rheumatism).

Smoking has been considered an important confounding factor that can mask any real effect of being overweight 22, as it is associated with weight reduction and an increased risk of death. Thus, we conducted analyses considering the anthropometric indicators in quartiles only among non-smokers, to minimize the residual confusion of this variable.

We conducted additional analyses with cut-off points commonly used in the literature for WC and BMI. WC was classified as increased when $\geq 80 \mathrm{~cm}$ and $<94 \mathrm{~cm}$ for women and $\geq 88 \mathrm{~cm}$ and $<102 \mathrm{~cm}$ for men, and substantially increased when $\geq 94 \mathrm{~cm}$ for women and $\geq 102 \mathrm{~cm}$ for men 23 . Underweight was defined as BMI $<18.5 \mathrm{~kg} / \mathrm{m}^{2}$, normal weight from 18.5 to $<25 \mathrm{~kg} / \mathrm{m}^{2}$, overweight from 25 to $<$ $30 \mathrm{~kg} / \mathrm{m}^{2}$ and obesity $\geq 30 \mathrm{~kg} / \mathrm{m}^{2}$, according to the cut-off points proposed by the World Health Organization (WHO) 24. All analyses were conducted with Stata version 13.0 (https://www.stata.com), except the database preparation, done with R version 3.4.1 (http://www.r-project.org).

\section{Results}

A total of 1,366 older adults (61.27\% women) participated in this study, aged 60 to 93 years. During a median 14-year follow-up, 672 participants died (287 men and 385 women), leading to 14,259 person-years of observation. The cohort's overall mortality rate was 47.12 per 1,000 person-years, being higher in men (55.40 per 1,000 person-years) than women (42.40 per 1,000 person-years) (p $<0.001)$. Cardiovascular diseases (16.62\%), cancer (7.32\%) and respiratory diseases (5.49\%) were the main causes of death in this population. 
At baseline, the medians of ABSI, WC, WHtR and BMI were significantly higher among women

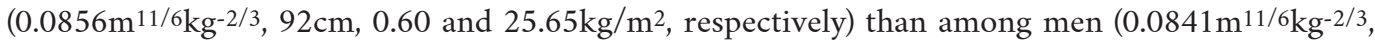
$89.50 \mathrm{~cm}, 0.54$ and $23.66 \mathrm{~kg} / \mathrm{m}^{2}$, respectively) $(\mathrm{p}<0.05)$. The median of anthropometric indicators measurements was 2.9 , ranging from one (16.50\%) to four (40\%).

Regarding the characteristics of the analyzed sample, most of the older adult participants were white (59.67\%), had four years of schooling or more $(37.52 \%)$, were non-current smokers $(83.50 \%)$, presented no at-risk alcohol consumption (95.18\%), were active (76.39\%) and presented negative serology for Trypanosoma cruzi (63.23\%). Gender showed a significant association ( $<0.05)$ with schooling, current smoking, at-risk of alcohol consumption, insufficient physical activity and positive serology for T. cruzi, in unadjusted analyses (Table 1).

Table 2 shows the results of the association between anthropometric abdominal adiposity indicators and mortality. Older adults in the fourth ABSI quartile had a higher risk of mortality $(\mathrm{HR}=1.32$, 95\%CI: 1.06-1.64) when compared with those in the first quartile, after adjustment for potential confounding factors; this association remained significant even after adjusting for BMI $(\mathrm{HR}=1.27,95 \% \mathrm{CI}: 1.02-1.58)$. Another abdominal adiposity indicator, WC, was associated with a lower risk of mortality in the third quartile after adjustment for confounders (HR $=0.77,95 \% \mathrm{CI}$ : 0.61-0.96), but this association disappeared when adjusted for BMI. When evaluated with cut-off points commonly used in the literature, WC showed no association with mortality after adjustment for selected variables or when adjusted for BMI. WHtR showed no association with mortality after adjustment for potential confounding factors or BMI.

\section{Table 1}

Characteristics of the studied sample according to gender. Bambui Cohort Study of Aging, Brazil (1997-2011).

\begin{tabular}{|c|c|c|c|c|}
\hline Variables & Total & Male & Female & p-value * \\
\hline Age in years [median (IQR)] & $67(63-72)$ & $66(62-72)$ & $67(63-72)$ & 0.203 \\
\hline \multicolumn{5}{|l|}{ Self-reported skin color } \\
\hline White & 59.67 & 62.05 & 58.29 & 0.054 \\
\hline Brown & 34.80 & 32.54 & 36.11 & \\
\hline Black & 5.53 & 5.41 & 5.60 & \\
\hline \multicolumn{5}{|l|}{ Schooling (years) } \\
\hline Illiterate & 28.85 & 24.62 & 31.32 & $<0.001$ \\
\hline $1-3$ & 33.63 & 35.71 & 32.41 & \\
\hline 4 or more & 37.52 & 39.67 & 36.27 & \\
\hline \multicolumn{5}{|l|}{ Current smoking } \\
\hline No & 83.50 & 72.61 & 89.88 & $<0.001$ \\
\hline Yes ** & 16.50 & 27.39 & 10.12 & \\
\hline \multicolumn{5}{|c|}{ At-risk alcohol consumption $* \star \star$} \\
\hline No & 95.18 & 87.52 & 99.65 & $<0.001$ \\
\hline Yes & 4.82 & 12.48 & 0.35 & \\
\hline \multicolumn{5}{|l|}{ Insufficient physical activity \# } \\
\hline No & 76.39 & 81.45 & 71.84 & $<0.001$ \\
\hline Yes & 24.61 & 18.55 & 28.16 & \\
\hline \multicolumn{5}{|c|}{ Positive serology for Trypanosoma cruzi } \\
\hline No & 63.23 & 69.44 & 59.60 & $<0.001$ \\
\hline Yes & 36.77 & 30.56 & 40.40 & \\
\hline
\end{tabular}

IQR: interquartile range.

Note: values expressed in percentages, except when specified.

* p-value of the Mann Whitney test or Pearson's chi-square test;

** Smoked 100 or more cigarettes during their lives and continued to smoke;

*** Consumed seven or more doses per week in the 12 months prior to the interview;

\# Less than 450 MET.minutes/week, considering all domains. 
Table 2

Univariate and multivariable analysis of the association between anthropometric abdominal adiposity indicators and mortality. Bambui Cohort Study of Aging, Brazil (1997-2011).

\begin{tabular}{|c|c|c|c|}
\hline \multirow[t]{2}{*}{ Anthropometric indicators * } & Unadjusted model & Model 1 & $\begin{array}{c}\text { Model } 2 \\
\text { (Adjusted for BMI) }\end{array}$ \\
\hline & $\begin{array}{c}\text { HR } \\
(95 \% \mathrm{Cl})\end{array}$ & $\begin{array}{c}\text { HR } \\
(95 \% \mathrm{Cl})\end{array}$ & $\begin{array}{c}\text { HR } \\
(95 \% \mathrm{Cl})\end{array}$ \\
\hline \multicolumn{4}{|l|}{ A body shape index $\left(\mathrm{m}^{11 / 6} \times \mathrm{kg}^{-2 / 3}\right)$} \\
\hline Q1 (reference: < 0.0812) & 1.00 & 1.00 & 1.00 \\
\hline Q2 (0.0812-0.0848) & $0.99(0.78-1.27)$ & $0.89(0.69-1.13)$ & $0.87(0.68-1.12)$ \\
\hline Q3 (0.0849-0.0887) & $1.20(0.96-1.51)$ & $0.99(0.79-1.25)$ & $0.97(0.77-1.23)$ \\
\hline Q4 (> 0.0887) & $1.88(1.52-2.32)$ & $1.32(1.06-1.64)$ & $1.27(1.02-1.58)$ \\
\hline \multicolumn{4}{|l|}{ Waist circumference $(\mathrm{cm})$} \\
\hline Q1 (reference: < 83.10) & 1.00 & 1.00 & 1.00 \\
\hline Q2 (84.10-91.00) & $0.76(0.62-0.92)$ & $0.89(0.73-1.10)$ & $0.96(0.77-1.19)$ \\
\hline Q3 (91.01-98.50) & $0.61(0.49-0.76)$ & $0.77(0.61-0.96)$ & $0.87(0.67-1.13)$ \\
\hline Q4 (> 98.50) & $0.68(0.55-0.83)$ & $0.86(0.69-1.06)$ & $1.06(0.76-1.45)$ \\
\hline \multicolumn{4}{|c|}{ Waist circumference (cm): cut-off points } \\
\hline Normal & 1.00 & 1.00 & 1.00 \\
\hline Increased & $0.71(0.58-0.86)$ & $0.84(0.68-1.03)$ & $0.90(0.71-1.12)$ \\
\hline Substantially increased & $0.64(0.54-0.76)$ & $0.82(0.67-1.01)$ & $0.95(0.72-1.24)$ \\
\hline \multicolumn{4}{|l|}{ Waist-to-height ratio } \\
\hline Q1 (reference: < 0.52) & 1.00 & 1.00 & 1.00 \\
\hline Q2 (0.52-0.57) & $0.80(0.65-0.98)$ & $0.93(0.75-1.14)$ & $1.00(0.80-1.25)$ \\
\hline Q3 (0.58-0.62) & $0.65(0.52-0.80)$ & $0.81(0.65-1.01)$ & $0.92(0.70-1.20)$ \\
\hline Q4 (> 0.62) & $0.68(0.55-0.84)$ & $0.84(0.67-1.05)$ & $1.03(0.74-1.43)$ \\
\hline
\end{tabular}

95\% Cl: 95\% confidence interval; BMI: body mass index; HR: hazard ratio.

Model 1: adjusted for age (continuous), gender, self-reported skin color, schooling, current smoking, at-risk alcohol consumption, insufficient physical activity and positive serology for Trypanosoma cruzi, as described in table 1.

Model 2: adjusted for the same variables as model 1 plus BMI (continuous).

* Divided in quartiles or cut-off points commonly used in the literature.

Older adults in the second, third and fourth BMI quartiles had a lower risk of mortality $(\mathrm{HR}=$ 0.79, 95\%CI: 0.64-0.96; HR = 0.71, 95\%CI: 0.57-0.88; HR = 0.69, 95\%CI: 0.55-0.86, respectively), association that remained even after adjustment for WC or ABSI (Table 3). For BMI evaluated with common cut-off points, we found that underweight older adults had a higher risk of mortality $(\mathrm{HR}=$ 1.42, 95\%CI: 1.11-1.80), while being overweight was a protective factor ( $\mathrm{HR}=0.82,95 \% \mathrm{CI}$ : 0.69-0.99), even after adjustment for WC or ABSI (Table 3).

Our analyses adjusted for health conditions such as hypertension, diabetes, cardiovascular diseases or respiratory diseases had no effect on the associations between anthropometric indicators and mortality (data not shown). However, to avoid controlling intermediate conditions in the causal path between obesity and mortality 25 and obtaining a more parsimonious model, we disregarded these variables in our final analyses.

Sensitivity analysis showed that ABSI had no association with mortality in a model adjusted for BMI, after excluding 59 deaths in the first two years of follow-up (30 men and 29 women), restricting analyses to non-smokers (813) or those without chronic illnesses at baseline (343). Excluding deaths in the first two years or restricting the analysis to non-smokers or those without diseases at baseline, resulted in sensitivity analysis for WC or WHtR adjusted for BMI with findings comparable to those of the total study population. For BMI, excluding deaths at the beginning of follow-up or restricting the analysis to non-smokers, did not change the results. Only the third quartile showed an inverse association with mortality in the analyses conducted with those without chronic diseases, in models adjusted for WC or ABSI. 
Table 3

Univariate and multivariable analysis of the association between body mass index (BMI) and mortality. Bambuí Cohort Study of Aging Brazil (1997-2011).

\begin{tabular}{|c|c|c|c|c|}
\hline \multirow[t]{2}{*}{ Anthropometric indicators * } & Unadjusted model & Model 1 & $\begin{array}{c}\text { Model } 3 \\
\text { (adjusted for WC) }\end{array}$ & $\begin{array}{c}\text { Model } 4 \\
\text { (adjusted for } \mathrm{ABSI} \text { ) }\end{array}$ \\
\hline & $\begin{array}{c}\text { HR } \\
(95 \% \mathrm{Cl})\end{array}$ & $\begin{array}{c}\text { HR } \\
(95 \% \mathrm{Cl})\end{array}$ & $\begin{array}{c}\text { HR } \\
(95 \% \mathrm{Cl})\end{array}$ & $\begin{array}{c}\text { HR } \\
(95 \% \mathrm{Cl})\end{array}$ \\
\hline \multicolumn{5}{|l|}{$\mathrm{BMI}\left(\mathrm{kg} / \mathrm{m}^{2}\right)$} \\
\hline Q1 (reference: < 21.77) & 1.00 & 1.00 & 1.00 & 1.00 \\
\hline Q2 (21.77-24.78) & $0.62(0.51-0.75)$ & $0.79(0.64-0.97)$ & $0.71(0.57-0.89)$ & $0.80(0.65-0.98)$ \\
\hline Q3 (24.79-28.00) & $0.52(0.21-0.64)$ & $0.71(0.57-0.88)$ & $0.59(0.45-0.78)$ & $0.71(0.57-0.88)$ \\
\hline Q4 (> 28.00) & $0.45(0.36-0.56)$ & $0.69(0.55-0.86)$ & $0.53(0.37-0.74)$ & $0.71(0.56-0.89)$ \\
\hline \multicolumn{5}{|l|}{ BMI (kg/m2): WHO cut-off points } \\
\hline Normal weight & 1.00 & 1.00 & 1.00 & 1.00 \\
\hline Underweight & $1.89(1.50-2.40)$ & $1.42(1.11-1.80)$ & $1.52(1.17-1.97)$ & $1.38(1.08-1.76)$ \\
\hline Overweight & $0.70(0.58-0.83)$ & $0.82(0.69-0.99)$ & $0.77(0.62-0.95)$ & $0.82(0.69-0.99)$ \\
\hline Obesity & $0.69(0.53-0.89)$ & $0.94(0.72-1.22)$ & $0.82(0.59-1.14)$ & $0.97(0.74-1.26)$ \\
\hline
\end{tabular}

95\%Cl: 95\% confidence interval; ABSI: a body shape index; HR: hazard ratio; WC: waist circumference; WHO: World Health Organization.

Model 1: adjusted for age (continuous), gender, self-reported skin color, schooling, current smoking, at-risk alcohol consumption, insufficient physical activity and positive serology for Trypanosoma cruzi, as described in Table 1;

Model 3: adjusted for the same variables as model 1 plus WC (continuous);

Model 4: adjusted for the same variables as model 1 plus ABSI (continuous).

* Divided in quartiles or cut-off points commonly used in the literature.

\section{Discussion}

This population-based cohort study using anthropometric measures, evaluated four times during follow-up, identified that a higher ABSI was directly associated with mortality independent of BMI; but this association was not found in the sensitivity analyses conducted. After adjusting for WC or ABSI, BMI remained inversely associated with mortality; while WC and WHtR showed no consistent associations with general mortality after adjusting for confounding factors.

International studies conducted in middle-aged and older adults populations found similar results regarding higher mortality risk among older adults with a high ABSI, when evaluating ABSI separately $26,27,28$. Conversely, a Chinese cohort study conducted with 780 middle-aged adults showed that ABSI was not associated with mortality 29.

In the present study, the direct association between ABSI and mortality changed only slightly when BMI was added to the model, showing its independence from BMI in the association with mortality 11 . Krakauer \& Krakauer 11 developed ABSI to be minimally associated with weight, height and BMI, so that it could be used in conjunction with the latter, to quantify the risk associated with abdominal obesity 30 . But few authors have assessed the combined contribution of ABSI and BMI to mortality 27 . A study conducted with 6,366 Dutch adults over the age of 55 showed that, when evaluated together, the direction and magnitude of the association for both ABSI and BMI remained similar, being comparable to the models that contained each measure separately 27.

The association between ABSI and a higher mortality risk observed among older adults in Bambuí and in other studies evaluating older populations $26,27,28$ may result from the fact that a high ABSI corresponds to greater abdominal (visceral) adiposity and a lower amount of lean mass, and the latter has been shown to have a strong negative correlation with mortality 31,32 . Adipose tissue, particularly visceral tissue, secretes potential mediators related to the development of chronic diseases 33 , which could explain why abdominal fat distribution, assessed by ABSI, was associated with a higher risk of death, regardless of BMI.

Although we found an association between ABSI and mortality for the total population of Bambuí, this association did not recur in the sensitivity analyses performed. Among the studies that evaluated 
the relationship between ABSI and mortality, only a few conducted analyses to limit the effects of residual confusion or reverse causality 27,28. A direct association between ABSI and mortality among 77,505 postmenopausal women persisted even after restricting analyses to non-smokers 28 . A study conducted with older Dutch adults observed similar results, and excluding deaths during the first five years of follow-up or participants who lost more than three kilograms of weight in the last 12 months prior to the study, did not substantially change the association measures when compared with the total study population 27 .

A recent meta-analysis verified that $\mathrm{ABSI}$ was a better predictor of mortality, when compared with BMI and WC 13. But this study conducted no analyses to assess potential residual confusion due to smoking or reverse causality due to existing diseases, which could affect the validity of the estimates obtained. Due to the limitations presented by this meta-analysis and the loss of significance in the association between ABSI and mortality in our sensitivity analyses, further studies are needed to confirm the hypothesis of association, in different populations, of this index and general mortality.

WC, another abdominal adiposity indicator, was associated with a lower risk of mortality in the third quartile, a result consistent with the assessment of WC with commonly used cut-off points; but this association did not recur after adjustment for BMI. Additionally, WHtR showed no association with mortality when assessed separately or adjusted by BMI.

Despite recommendations endorsing the use of WC and BMI in clinical practice 34 , these indicators are strongly correlated, hindering to assess the independent contribution of abdominal adiposity to mortality 10 . But a meta-analysis including 58,609 adults aged 65 to 74 years, showed that increased WC was associated with a higher mortality risk, independent of BMI. In this study, the authors reported absence of multicollinearity among the anthropometric indicators assessed as continuous variables, showing the independent role of abdominal adiposity in mortality 35 . On the other hand, our results showed that after adjusting for BMI, WC lost its association with mortality, while WC evaluated with cut-off points showed no association with the outcome in any of the adjusted models. In the population of Bambuí, WC and BMI showed a correlation of 0.78, suggesting that WC is not only an indicator of abdominal adiposity, but also of general adiposity, as already reported by other authors 36 .

Some studies have shown inconsistent associations between WC and mortality when the analyses are adjusted for BMI $27,37,38$ or even in models that evaluated WC separately $36,39,40$. A study conducted with older North American adults showed that WC had a negative association with mortality, which became positive after adjusting for BMI ${ }^{37}$. Two other studies found that the association between WC and mortality was evident only after adjusting for BMI 27,38. The discrepancies found when adjusting the model by another indicator may result from the collinearity between BMI and WC. However, none of these studies reported having performed analyses to diagnose multicollinearity.

Besides the limitation due to the lack of multicollinearity assessment, there could be other explanations to the conflicting results of studies that assess the relationship between waist circumference and mortality. Among these issues are the adjustment for mediating variables, ethnic differences in body composition, selection of older adults from different age groups and selective survival. Due to these discrepancies, further studies with standardized methods are needed to verify whether WC should be used to assess mortality risk among older adults.

As for the general adiposity indicator, we found that older adults in the second, third and fourth BMI quartiles had a lower risk of mortality, even after adjusting for WC or ABSI, as well as in the analyses using the cut-off points proposed by the WHO. The sensitivity analyses for BMI had results comparable to those obtained for the total population, providing additional evidence that residual confusions due to smoking or weight loss from pre-existing serious illness could not fully explain our results. These findings are consistent with the results of previous systematic reviews and metaanalyses, which showed that overweight is a protective factor for mortality among older adults 3,41 . The association between BMI and mortality, regardless of ABSI, is in line with the findings of a Dutch study 27 , which showed the importance of total adiposity in all-cause mortality, regardless of abdominal adiposity.

This study has some strong points, such as anthropometric indicators obtained from direct measurements of weight, height and WC, as self-reported data can result in incorrect classification of individuals ${ }^{42}$. Additionally, we considered anthropometric measurements obtained at four different 
times, instead of only at baseline, different from most longitudinal (or cohort) studies investigating this topic. Despite these positive points, this study has some limitations. First, information on pre-existing chronic condition for cancer, which is associated with low body weight or low BMI, was unavailable and could have potentially confused the observed associations. Finally, although we adjusted our study for several confounding factors, due to its observational nature, we must consider the possibility of residual confusion.

\section{Conclusions}

Our results showed that ABSI, evaluated at four moments of follow-up, was associated with a higher risk of mortality regardless of BMI, but this association receded after sensitivity analyses, suggesting a possible weakness of this index in predicting mortality. Thus, using ABSI in clinical practice or for assessing risks associated with overweight in epidemiological surveys, in conjunction or replacing BMI and WC, still needs more in-depth studies, including those conducted with older adults. However, given the consistency of associations verified for BMI, our results corroborate the fact that this index remains, at least regarding mortality, as the best indicator of this outcome among older adults.

\section{Contributors}

M. A. Nascimento-Souza contributed on the study design, analysis and final writing of the article. J. V. M. Mambrini and S. V. Peixoto collaborated in data analysis and revised the manuscript. M. F. Lima-Costa participated in the project design and analysis, relevant critical review of the manuscript's intellectual content and approval of the final version, being also responsible for its content.

\section{Additional informations}

ORCID: Mary Anne Nascimento-Souza (00000002-3525-6554); Juliana Vaz de Melo Mambrini (0000-0002-0420-3062); Sérgio Viana Peixoto (0000-0001-9431-2280); Maria Fernanda LimaCosta (0000-0002-3474-2980).

\section{Acknowledgments}

We thank the Brazilian National Research Council (CNPq).

\section{References}

1. Prospective Studies Collaboration; Whitlock G, Lewington S, Sherliker P, Clarke R, Emberson J, et al. Body-mass index and cause-specific mortality in 900000 adults: collaborative analyses of 57 prospective studies. Lancet 2009; 373:1083-96.

2. Parr CL, Batty GD, Lam TH, Barzi F, Fang $\mathrm{X}$, Ho SC, et al. Body-mass index and cancer mortality in the Asia-Pacific Cohort Studies Collaboration: pooled analyses of 424,519 participants. Lancet Oncol 2010; 11:741-52.

3. Winter JE, MacInnis RJ, Wattanapenpaiboon N, Nowson CA. BMI and all-cause mortality in older adults: a meta-analysis. Am J Clin $\mathrm{Nu}-$ tr 2014; 99:875-90.

4. Nuttall FQ. Body mass index: obesity, BMI, and health: a critical review. Nutr Today 2015; 50:117-28.

5. Harris TB, Visser M, Everhart J, Cauley J, Tylavsky F, Fuerst T, et al. Waist circumference and sagittal diameter reflect total body fat better than visceral fat in older men and women. The Health, Aging and Body Composition Study. Ann N Y Acad Sci 2000; 904:462-73.

6. Gallagher D, Visser M, Sepulveda D, Pierson RN, Harris T, Heymsfield SB.How useful is body mass index for comparison of body fatness across age, sex, and ethnic groups? Am J Epidemiol 1996; 143:228-39. 
7. Cerhan JR, Moore SC, Jacobs EJ, Kitahara CM, Rosenberg PS, Adami HO, et al. A pooled analysis of waist circumference and mortality in 650,000 adults. Mayo Clin Proc 2014; 89:33545.

8. World Health Organization. Waist circumference and waist-hip ratio: report of a WHO Expert Consultation, 2008. http://whqlibdoc whoint/publications/2011/9789241501491_ eng.pdf (accessed on Jan/2020).

9. Ehrampoush E, Arasteh P, Homayounfar R, Cheraghpour M, Alipour M, Naghizadeh MM, et al. New anthropometric indices or old ones: which is the better predictor of body fat? Diabetes Metab Syndr 2017; 11:257-63.

10. Moore SC. Waist versus weight: which matters more for mortality? Am J Clin Nutr 2009; 89:1003-4.

11. Krakauer NY, Krakauer JC. A new body shape index predicts mortality hazard independently of body mass index. PLoS One 2012; 7:e39504.

12. Hsieh SD, Yoshinaga H, Muto T. Waist-toheight ratio, a simple and practical index for assessing central fat distribution and metabolic risk in Japanese men and women. Int J Obes Relat Metab Disord 2003; 27:610-6.

13. Ji M, Zhang S, An R. Effectiveness of A Body Shape Index (ABSI) in predicting chronic diseases and mortality: a systematic review and meta-analysis. Obes Rev 2018; 19:737-59.

14. Giudici KV, Martini LA. Comparison between body mass index and a body shape index with adiponectin/leptin ratio and markers of glucose metabolism among adolescents. Ann Hum Biol 2017; 44:489-94.

15. Instituto Brasileiro de Geografia e Estatística. Síntese de indicadores sociais. Uma análise das condições de vida. https://biblioteca.ibge.gov. br/visualizacao/livros/liv66777.pdf (accessed on Jan/2020).

16. Kehdy FS, Gouveia MH, Machado M, Magalhães WC, Horimoto AR, Horta BL, et al. Origin and dynamics of admixture in Brazilians and its effect on the pattern of deleterious mutations. Proc Natl Acad Sci USA 2015; 112:8696701.

17. Lima-Costa MF, Firmo JO, Uchoa E.Cohort profile: the Bambui (Brazil) Cohort Study of Ageing. Int J Epidemiol 2011; 40:862-7.

18. Barreto SM, Passos VMA, Lima-Costa MF. Obesity and underweight among Brazilian elderly: the Bambuí Health and Aging Study. Cad Saúde Pública 2003; 19:605-12.

19. Lima-Costa MF, Peixoto SV, Matos DL, Firmo JO, Uchôa E. Predictors of 10-year mortality in a population of community-dwelling Brazilian elderly: the Bambuí Cohort Study of Aging. Cad Saúde Pública 2011; 27 Suppl 3:S360-9.

20. Flanders WD, Augestad LB. Adjusting for reverse causality in the relationship between obesity and mortality. Int J Obes (Lond) 2008; 32 Suppl 3:S42-6.

21. Carslake D, Jeffreys M, Davey Smith G. Being overweight in early adulthood is associated with increased mortality in middle age. Sci Rep 2016; 6:36046.
22. Manson JE, Stampfer MJ, Hennekens CH, Willett WC. Body weight and longevity. A reassessment. JAMA 1987; 257:353-8.

23. Lean ME, Han TS, Morrison CE. Waist circumference as a measure for indicating need for weight management. BMJ 1995; 311:15861.

24. World Health Organization. Physical status: the use and interpretation of anthropometry. Report of a WHO Expert Committee. https:// www.who.int/childgrowth/publications/phys ical_status/en/ (accessed on Jun/2019).

25. Hu FB. Obesity and mortality. In: Hu FB. Obesity epidemiology. New York: Oxford University Press; 2008. p. 216-33.

26. Wierup Ia, Carlsson AC, Wändell P, Riserus U, Ärnlöv J, Borné Y. Low anthropometric measures and mortality: results from the Malmö Diet and Cancer Study. Ann Med 2015; 47:325-31.

27. Dhana K, Kavousi M, Ikram MA, Tiemeier HW, Hofman A, Franco OH. Body shape index in comparison with other anthropometric measures in prediction of total and causespecific mortality. J Epidemiol Community Health 2016; 70:90-6.

28. Thomson CA, Garcia DO, Wertheim BC, Hingle MD, Bea JW, Zaslavsky O, et al. Body shape, adiposity index, and mortality in postmenopausal women: findings from the women's health initiative. Obesity (Silver Spring) 2016; 24:1061-9.

29. He S, Zheng Y, Wang H, Chen X.Assessing the relationship between a body shape index and mortality in a group of middle-aged men. Clin Nutr 2017; 36:1355-9.

30. Krakauer NY, Krakauer JC. Dynamic association of mortality hazard with body shape. PLoS One 2014; 9:e88793.

31. Krakauer NY, Krakauer JC. Expansion of waist circumference in medical literature: potential clinical application of a body shape index. J Obes Weight Loss Ther 2014; 4:216.

32. Gomez-Peralta F, Abreu C, Cruz-Bravo M, Alcarria E, Gutierrez-Buey G, Krakauer NY, et al. Relationship between "a body shape index (ABSI)" and body composition in obese patients with type 2 diabetes. Diabetol Metab Syndr 2018; 10:21.

33. Haslam DW, James WP. Obesidade. Lancet 2005; 366:1197-209.

34. Janssen I, Heymsfield SB, Allison DB, Kotler DP, Ross R. Body mass index and waist circumference independently contribute to the prediction of nonabdominal, abdominal subcutaneous, and visceral fat. Am J Clin Nutr 2002;75:683-8.

35. de Hollander EL, Bemelmans WJ, Boshuizen HC, Friedrich N, Wallaschofski H, GuallarCastillón $\mathrm{P}$, et al. The association between waist circumference and risk of mortality considering body mass index in 65- to 74-yearolds: a meta-analysis of 29 cohorts involving more than 58,000 elderly persons. Int J Epidemiol 2012; 41:805-17. 
36. Reis JP, Macera CA, Araneta MR, Lindsay SP, Marshall SJ, Wingard DL. Comparison of overall obesity and body fat distribution in predicting risk of mortality. Obesity (Silver Spring) 2009; 17:1232-9.

37. Janssen I, Katzmarzyk PT, Ross R. Body mass index is inversely related to mortality in older people after adjustment for waist circumference. J Am Geriatr Soc 2005; 53:2112-8.

38. Guallar-Castillón P, Balboa-Castillo T, LópezGarcía E, León-Muñoz LM, Gutiérrez-Fisac JL, Banegas JR, et al. BMI, waist circumference, and mortality according to health status in the older adult population of Spain. Obesity (Silver Spring) 2009; 17:2232-8.

39. Dolan CM, Kraemer H, Browner W, Ensrud K, Kelsey JL. Associations between body composition, anthropometry, and mortality in women aged 65 years and older. Am J Public Health 2007; 97:913-8.
40. Pujilestari CU, Nyström L, Norberg M, Ng $\mathrm{N}$. Waist circumference and all-cause mortality among older adults in rural Indonesia. Int J Environ Res Public Health 2019; 16:116.

41. Jiang M, Zou Y, Xin Q, Cai Y, Wang Y, Qin $\mathrm{X}$, et al. Dose-response relationship between body mass index and risks of all-cause mortality and disability among the elderly: a systematic review and meta-analysis. Clin Nutr 2019; 38:1511-23.

42. Spencer EA, Appleby PN, Davey GK, Key TJ. Validity of self-reported height and weight in 4808 EPIC-Oxford participants. Public Health Nutr 2002; 5:561-5. 


\section{Resumo}

O estudo teve como objetivo avaliar a associação isolada e independente entre indicadores de adiposidade abdominal e indice de massa corporal (IMC) e mortalidade. O estudo usou dados de 1.366 idosos que tinham informações completos para todas as variáveis independentes no Estudo de Coorte de Idosos de Bambuí, Brasil. A variável dependente foi o tempo até o óbito por todas as causas, e as variáveis de exposição foram o indice de forma corporal (a body shape index - ABSI), circunferência de cintura (CC), razão cintura/estatura (RCE) e IMC, medidos na linha de base e aos 3o, $5 \underline{o}$ e 11 o anos de seguimento. A associação entre os quartis de indicadores antropométricos e a mortalidade foi investigada usando um modelo estendido de riscos proporcionais de Cox ajustado por fatores de confusão socioeconômicos e comportamentais. Os idosos do 40 quartil do ABSI mostraram maior risco de mortalidade, independentemente de IMC (1,27; IC95\%: 1,01-1,58), mas a associação não foi mantida nas análises de sensibilidade. Os idosos do 2o, $3 \underline{\text { o e }}$ 4o quartis de IMC mostraram risco menor de mortalidade, associação esta que foi mantida após ajustar para CC ou ABSI. Por outro lado, a CC e a RCE não mostraram associações consistentes com a mortalidade geral depois de ajustar para fatores de confusão. As análises mostraram que a capacidade preditiva do ABSI para mortalidade ainda é fraca, considerando a perda de significância nas análises de sensibilidade. Portanto, a possibilidade de adoção do ABSI na prática clínica ou em inquéritos epidemiológicos para complementar ou substituir o IMC e CC ainda precisa ser explorada com maior profundidade em estudos futuros.

Envelhecimento; Mortalidade; Índice de Massa Corporal; Circunferência de Cintura;

Razão Cintura-Estatura

\section{Resumen}

El objetivo de este artículo es evaluar la asociación conjunta y separada entre los indicadores de adiposidad abdominal y general, y la mortalidad. Los datos se recogieron de 1.366 adultos mayores en el estudio de Cohorte Ancianos de Bambuí, Brasil, con información completa para todas las variables de interés. El resultado de la variable fue por cualquier causa hasta la muerte; las variables de exposición fueron indice de forma corporal (a body shape index - ABSI por sus siglas en inglés), circunferencia de cintura (WC), proporción cinturaaltura (WHtR) e indice de masa corporal (BMI), evaluados al principio del estudio, y en el 3o, 5o y 11 o año de seguimiento. Se calculó la asociación entre los cuartiles de indicadores antropométricos y mortalidad, usando un modelo extendido de Cox de riesgos proporcionales, $y$ ajustado por factores de confusión socioeconómicos y comportamentales. Los adultos más viejos en el 4o cuartil ABSI tuvieron un riesgo mayor de mortalidad, independientemente del BMI (1,27; 95\%CI: 1,01-1,58), pero esta asociación no fue observada en los análisis de sensibilidad. Los adultos más viejos en los 2o, $3 \underline{o} y$ 4o cuartiles de BMI tuvieron un riesgo más bajo de mortalidad, incluso cuando fue ajustado por WC o ABSI. WC y WHtR no mostraron asociación consistente con todas las causas de mortalidad tras el ajuste para factores de confusión. Considerando la pérdida de significación en los análisis de sensibilidad, la capacidad predictiva de ABSI para la mortalidad es todavía débil. De este modo, adoptar ABSI en la práctica clínica o en encuestas epidemiológicas, en conjunción o reemplazando BMI y $W C$, requiere más estudios en profundidad.

Envejecimiento; Mortalidad; Índice de Masa Corporal; Circunferencia de la Cintura; Relación Cintura-Estatura
Submitted on $29 / \mathrm{Jan} / 2020$

Final version resubmitted 09/May/2020

Approved on 15/May/2020 